\title{
An interest balancing mechanism analysis of Greater Mekong Subregion (GMS) Economic Corridors
}

\author{
Wu Qiong* \\ International Business School \\ Yunnan University of Finance and Economics \\ Kunming, China \\ 13512408792@163.com
}

\author{
Yu Yong \\ International Business School \\ Yunnan University of Finance and Economics \\ Kunming, China \\ yuyong01@vip.163.com
}

\begin{abstract}
Greater Mekong Subregion (GMS) hinterland involving many countries and regions in Southeast Asia and South Asia, is one of the most dynamic regions in the world today .The mission of GMS economic cooperation is to expand and strengthen the cooperation among each subregion country, and realize common economic development, achieve a balance of construction interests. However, the unbalanced economic development of six countries leads to quite different levels of economic development of countries. From collaborative planning perspective, each plan would bring each country the same benefits, and it is the key point about whether the GMS economic cooperation goes on smoothly, and enable countries to obtain their corresponding share and interests, achieve mutual benefit and common development. Based on which, the balance of interest mechanism were analyzed by four aspects of economic, energy, environmental protection and transportation.
\end{abstract}

Keywords-GMS ; subregion economic cooperation ; benefit balance mechanismt

\section{INTRODUCTION}

GMS is now one of the world's fastest growing economy regions. In 1992, in order to strengthen economic relationship among the member states, promote economic and social development in the region and enhance the international competitiveness of the subregion, at the initiative of the Asian Development Bank, the six countries along the Mekong River established the Greater Mekong Subregion (GMS) economic cooperation mechanism. The cooperation is based on equality, mutual trust and mutual benefit, through the mechanism of strengthening economic ties among developing countries, and promoting economic and social coordinated development of subregion.Greater Mekong Subregion has made remarkable achievements after 20 years of development. From the collaborative projects and the amount of investment perspective, the GMS member countries with nine key areas of cooperation carried out more than 260 cooperation projects with the investment capital about $\$ 17$ billion in transport, energy, telecommunications, environment, agriculture human resource development, tourism, trade facilitation [6]

\footnotetext{
* Corresponding author
}

\section{A. Traffic Infrastructure Interconnection}

In 2015, the Greater Mekong Subregion Economic Cooperation Transport Infrastructure interconnection continues to advance further. On March 11, the first plenary meeting of the Greater Mekong River Railway Alliance is held in Kunming, Yunnan Province, China. China, Cambodia, Laos, Myanmar, Thailand, Vietnam, six member states and representatives of the Asian Development Bank attend the meeting. The meeting has in-depth discussions on accelerating the formation of sub-regional railway alliances mechanism and promoting subregional rail transport integration. The railways Unicom has also been able to continue to progress among Sub-regional countries. In June 2015, the Thai government announces that it would jointly build a fast railway with a length of 873 kilometers from Bangkok to Gallery. On March 5, 2015, Thai Nong Khai to Laos Tana Leng's international railway transport line has officially opened to traffic. On November 13, 2015, the China Laos railway project signs and officially enters the implementation stage, and has established a good foundation in the terms of the construction of the project and the two countries to further strengthen the railway infrastructure cooperation. In December 5, connecting the capital of Vientiane in Laos and Kunming, Yunnan, the China Laos railway Laos section (Boten to Vientiane) held groundbreaking ceremony, marking the total length of 417 kilometers' China Laos railway officially starts construction. In the territory of China Yuxi - Mohan railway has also started construction in early 2016. On May 9, 2015, the old Burmese Friendship Bridge, which connects Laos 17 and Myanmar 4 Highway, is officially opened.

\section{B. Trade, investment areas}

According to statistics, the China-Laos bilateral trade volume of $\$ 2.78$ billion in 2015 . The Sino-Thai bilateral trade volume of $\$ 75.46$ billion, an increase of $3.8 \%$. Among them, China exports $\$ 38.29$ billion to Thailand, an increase of $11.6 \%$; imports $\$ 37.17$ billion, an decrease of $3.1 \%$. In terms of investment, China's direct investment in Laos non-financial sector exceeds $\$ 1$ billion to $\$ 1.36$ billion in 2015 , a rise of $36.2 \%$ year-on-year. By the end of 2015, Laos accumulates actual investment of $\$ 45.49$ million in China.By the end of 
2015, China's direct investment stock of $\$ 3.52$ billion in Thailand. In 2015, China's direct investment in Thailand \$ 440 million, an increase of $21.1 \%$, Thailand and China accumulate actual investment of $\$ 4.06$ billion. Thailand is the largest trading partner and an important source of investment for Laos. By 2015, Thailand's total investment in Laos has exceeded US $\$ 3$ billion, mainly in metal processing, machinery and equipment manufacturing, textile and clothing, leather, footwear, electronics, plastic products and other processing and manufacturing industries. In March 2015, Laos and Thailand negotiate setting up a bilateral joint committee as a mechanism for advancing economic cooperation in all directions to promote bilateral trade, investment, logistics, retail and wholesale services [8].

\section{Tourism cooperation area}

In 2015, the number of Chinese tourists to the Mekong River five countries has risen to 12.8 million, and China has become the largest tourist country in Vietnam and Thailand. On 18 June, subregional countries organize an annual tourism forum on the theme "Better development of the Greater Mekong Subregion tourism potential through the new partnership" in Da Nang, Viet Nam, and the participating countries have conducted in-depth discussions on how to further promote the facilitation of tourism within the subregion.

\section{The situation of electric power cooperation construction}

In 2015, the Greater Mekong Subregion power cooperation has also made new progress. Among them, China and Laos and Vietnam's power cooperation with remarkable results. From the beginning of 2009, China Southern Power Grid begins interconnection with Laos and transmits power to Laos. As of October 2015, China has transmitted 892 million kwh power to Laos, making an important contribution for the northern power supply in Laos. On November 29, 2015, "The Belt and Road" the first grid cooperation project - $230 \mathrm{kV}$ Laos North Power Grid project power transfer ceremony is held in Luang Prabang, Laos. The project spans four provinces in northern Laos, including four $230 \mathrm{kV}$ lines and four substations with a contract value of $\$ 302$ million. The grid project ended the history which single operation of the Laos northern grid, forming a unified national $230 \mathrm{kV}$ backbone grid. The Vietnam Yongxin coal-fired power plant project which invested by China Southern Power Grid Corporation, also starts to construct on July 18, 2015. The project adopts BOT mode of operation, which is the largest investment project of Chinese enterprises in Vietnam so far. The project construction period is 4 years, the franchise period is 25 years, and after the expiration of the operation will be handed over to the Vietnamese government free of charge[8].

In terms of geographical distribution of economic cooperation projects, the space layout features of North-South east-west corridor has been formed. From bilateral trade among China and other countries in the Greater Mekong Subregion, the trade structure has been gradually improved, and the bilateral investment has also made rapid growth. It has achieved remarkable progress and effectiveness in promoting regional economic integration, regional economic and social development and the international competitiveness of the subregion. Nonetheless, with the implementation of the project, the natural resources in the countries of the region or regions varied with different due to the diversity in countries' economic situation, location, environment, human, institutional and other aspects.Therefore, they have different levels of development and interest demands, some of whom pursue long-term interests, some have the pursuit of immediate interest, some pursuit of direct interest, while others are focused on indirect benefits. Thus, establishing an effective benefits balanced mechanism is particularly important for a range of disputes arising from interests [1].

\section{The ACCOMPLiShMENT OF BENEFIT BALANCE MECHANISM IN ECONOMIC DIFFERENCE}

Countries in the Greater Mekong Subregion are mostly typical agricultural country, which are relatively weak in industrial base. Even Thailand, which has entered the ranks of the newly industrialized countries, its agricultural output account for about $35 \%$ of its gross domestic product, particularly the north is still based on agricultural production[2]

The structure of foreign trade is unbalanced. In addition to Thailand and China, whose major export commodities are manufactured goods, the degree of development in the subregion is relatively low in Vietnam, Myanmar, Laos, Cambodia whose structure of foreign trade are mainly agricultural and mineral resources of primary products, have poor international competitiveness.

Balance of trade is unbalanced. Except that Thailand and China have a foreign trade surplus, Vietnam, Myanmar, Laos, Cambodia, they are facing economic problems in foreign trade deficit, may reduce the trade deficit, or may be closed; or may lower trade barriers and expand trade deficit, go to the dilemma of open.

The role of trade-driven economic growth is out of balance.In addition to Thailand, China, Vietnam, whose foreign trade promoted their economic growth obviously, Myanmar, Laos, Cambodia have emerged as a small number of export commodities, few varieties, low technical content and added value, and their foreign trade has failed to become the power of economic growth.

the capital flow is unbalanced. Except China and Thailand in Subregion, which possess the ability to flow in and out of capital, other countries do not have the ability on external investment, and are countries with net inflow of capital.

The size and level of trade and investment is low. Except Thailand, Yunnan and Guangxi province in China, Vietnam, Laos, Myanmar and Cambodia are less developed countries or regions, the level of their economic and social development are at a low level, which determines that these countries' trade and investment can only be at low level and scale within a period of time[2].

Therefore, to achieve the balance of interests of the six countries in Greater Mekong Subregion, we should deepen regional division of labor, establish competitive industries, and promote the development with a competitive advantage. The 
scarcity of capital, technology and human resources has been the main reason that the sub-regional economic development is restrained, the international division of labor among the countries in subregion, must make full use of local advantages of resources to build industry. In terms of trade and investment, the national economic and the structure of export commodities in sub-regional countries is not the same, and their import and export commodities have strong complementarity and similarity.Reducing or eliminating the trade barriers enables each country to establish industries with comparative advantage, to reduce production costs and to improve the competitiveness of complementarity, which crowds out some of the export products of the same type, resulting in trade diversion effect. Meanwhile, the subregional countries have strong similarity in exports commodities, which aggravates the competition, and promotes the concentration of production, produces economies of scale, optimizes the allocation of economic resources $t$ in this region, resulting in trade creation effect. Therefore, we should continue to deepen regional division of labor, promote the achievement of trade creation and trade diversion.In the low level of economic development countries like Vietnam, Myanmar, Cambodia, Laos, they should focus on the development of labor and contracted projects, to speed up infrastructure construction, improve the environment of trade and investment, to export from mere resources, gradually develop processing trade, and promote the process of industrialization.

\section{THE ACHIEVEMENT OF THE BALANCE OF INTERESTS IN ENERGY DEVELOPMENT AND ENVIRONMENTAL PROTECTION MECHANISMS}

GMS is rich in water resources, biological resources, mineral resources, which has great economic potential and development prospects. The countries in GMS, Myanmar, Laos with rich hydropower resources contain a huge amount of water, but a lower rate of exploitation, have a huge potential for further development and utilization. Vietnam, Thailand possess abundant coal, oil and gas resources. Sub-regional oil and gas resources are mainly distributed in Vietnam, Thailand and Myanmar these three countries, and on the reserves, the oil resource of Myanmar is well stocked, followed by Vietnam. Natural gas is the most abundant resource in Thailand, followed by Myanmar. Differences in energy distribution make the national energy shortage in varying degrees[5].

Although the sub-regional resource is rich, but the overall development exploitation rate is low with the unbalanced national hydroelectric energy development and uneven distribution of electricity area, and due to the small area of countries and regions in the subregion, in addition to Cambodia, other countries along the river appears a north south strip. The countries have elongated grid self-contained national systems, which will lead to the north-south longdistance transmission, and the transmission wastage is large. Therefore, the country can adopt the nearby principle to allocate resources, and establish a unified subregional power grid, achieving a rational use of energy in the subregion as a whole, so as to achieve the balance of interests[3].

Because the natural environment of the Greater Mekong River Basin is extremely complex, they must pay attention to the coordinated development and environmental protection in the development process, otherwise it will affect not only the interests of developed countries, also will give adverse impact on regional cooperation. On the one hand, they should put the environmental safety of the part of hydropower development into the environmental safety of the entire Mekong River Basin to consider.

As a cross-border river, the water resources development in the Greater Mekong River Basin make water security in the region an important factor affecting the security of the region, which not only involves non-traditional security issues, ecological and economic, but also affects the political mutual trust sovereignty and other traditional security issues.

China should fully grasp the good opportunity of the surrounding diplomatic strategy to build an international platform environment of sub-regional cooperation, and adopt the development of Lancang River hydropower resources into the establishment of China - ASEAN Free Trade Area of the conception, as well as the southwest China's national security strategic consideration[4]. On the other hand, we should establish a stable support system, strengthen the analysis of research and data collection in sub-regional, and proceed as soon as possible to establish sub-regional organizations to support environmental research, and complete biodiversity and technical reserves research in subregion. Based on the principle of mutual cooperation and risk-sharing, we should establish a sincere and cooperative relationship in issues research and policy-making[7].

\section{IMPLEMENTION OF TRANSPORTATION PROJECTS PLANNED IN THE INTERESTS OF BALANCE MECHANISM}

During the road construction plan in the GMS Economic Area, the Kunming-Bangkok Highway and Trans-Asian Railway construction are the major projects in the Greater Mekong Subregion Economic Cooperation.

The basic trend of Kunming-Bangkok highway is exit from Mengla of Xishuang banna in China through northern Laos Oudomxay, South Tower, the territory pocho province, and enter River into Thailand town of Chiang Khong in multinational Mekong, together with Thailand's road network. Trans-Asian Railway from Yunnan Kunming in China, west line from Laos, Myanmar, Thailand into Malaysia, Singapore, the east by Vietnam, Cambodia, Thailand, Malaysia, and finally arrive Singapore. From the above we can see the route, two transport projects neglects northeastern Thailand and Laos Vientiane region, and these two areas are the two important economic areas, thus leading to unbalanced regional development and producing uneven distribution of the countries' interests[8]. The consideration of the construction of a road or railway through the two regions should be a good supplement of "two vertical and two horizontal".

The basic trend of Nanning - Bangkok railway is from Nanning through Friendship Gate into the territory of Vietnam, arriving in Hanoi then across the west, peace, Son La province, Laos, Vietnam border enter into Laos Houaphan Province, Xieng Khouang, and arrive Vientiane through the Friendship bridge on the Mekong River into Thailand, Bangkok straight from Nong Khai. Such trend is almost a straight line, 
connecting Bangkok, Vientiane, Hanoi, Beijing on a railway line, making it more favorable to achieve the interests of balancing mechanism of Mekong countries.

\section{CONCLUSION}

Currently, there are all kinds of cooperation mechanism in GMS, and the interest relationship, strategies motivation, background among different mechanisms, and on how to balance the interests of all parties need to strengthen communication and coordination between the mechanisms, coordinate the relationship, avoid overlapping functions on a variety of behaviors, coordinate and supervise the behavior of countries, establish institutionalized interest negotiation mechanism, define the role in the mechanism, and form an institutionalized dispute settlement mechanism in order to achieve the true balanced development.

\section{ACKNOWLEDGMENT}

First of all, I would like to express my deep gratitude to Professor $\mathrm{Yu}$ Yong, supervisor of my dissertation, for having continually stimulated me with her methodological concerns and persistent guidance in both realms of studies and life during the period of my writing the work, wish to thank him sincerely for his tolerance and openness which nurtured my interest in the present work. Now I consider it a great privilege to have got the benefit of his professional guidance.

\section{REFERENCES}

[1] S.H. Bi, "Summary of the international academic symposium of 'Building Economic Corridor in Greater Mekong Sub-region: cooperation and development'," Contemporary Asia-Pacific Studies, 2008, pp. 139-142.

[2] S. He, and X. Li, "Cooperation Situation and Problems of Greater Mekong Sub-region Economic," Asia\& Africa Review, 2008, pp. 3-48.

[3] Z. Liu, "Study on the Economic Corridor construction of Great Mekong Sub-region," Yunnan University Press, 2009, pp. 20-24.

[4] T.C. H. Sunderland, J. Sayer and M.H. Hoang, "Evidence-based conservation: lessons from the Lower Mekong," Evidence-based conservation: lessons from the Lower Mekong, 2012.

[5] J. Cheng and Z.J. Wang, "Greater Mekong Sub-region Power Trade Center Design and Policy Suggestions," Water Resources and Power, 2013, pp. 219-222.

[6] Z.X. Guo, "Greater Mekong Sub-region Cooperation Research:Review and Analysis," Southeast Asian Aspect Ratio, 2013, pp. 72-78.

[7] Y. Wang, and Z. Lin, "Strengthening Environmental Cooperation in Greater Mekong River, Providing Strategic Environmental Support for 'One Belt One Road'," Environment and Sustainable Development, 2015, pp. 9-12.

[8] Z. Liu, "Report on the Cooperation and Development in the Greater Mekong Sub-region," Bei Jing: Society Science Document Press, 2016, pp. 26-28. 